\section{Vitrectomy for primary symptomatic vitreous opacities: an evidence-based review}

T Ivanova1', A Jalil' ${ }^{1}$, Y Antoniou' ${ }^{1}$, PN Bishop ${ }^{1,2}$, $J \mathrm{~L}$ Vallejo-Garcia ${ }^{1,3}$ and N Patton ${ }^{1}$

\begin{abstract}
Floaters are a common ocular condition which form as a consequence of aging changes in the vitreous. Although in most patients the symptoms are minimal, they can cause significant impairment in vision-related quality of life in a small population of patients. Recently there has been an increase in awareness of the visual disability caused by floaters, and the evidence-base for treatment of this condition using small-gauge vitrectomy has increased. In this review, we define the term 'floaters' as symptomatic vitreous opacities (SVO). We suggest a classification dependent on the presence or absence of posterior vitreous detachment and discuss their pathogenesis and natural history. We review their impact on patients' quality of life related to visual function. We review the psychological factors that may have a role in some patients who appear to be affected by SVO to the extent that they pursue all options including surgery with all its attendant risks. We summarise the available evidence-base of treatment options available for SVO with special emphasis on the safety and efficacy of vitrectomy for this condition.

Eye (2016) 30, 645-655; doi:10.1038/eye.2016.30; published online 4 March 2016
\end{abstract}

\section{Introduction and definition of terms}

The symptom of floaters is one of the most common albeit least treated ocular conditions. They form as a result of alterations in the vitreous structure, usually as a consequence of age-related changes. Generally vitreous floaters are of little clinical significance with minimal impact on the quality of vision of patients, but there is a small population of patients with debilitating floaters greatly affecting their quality of life. ${ }^{1}$ We define symptomatic vitreous opacities (SVO) as floaters severe enough to cause symptoms for a minimum time period of 3 months, and which cause enough visual disturbance for the patient to explore therapeutic options. The duration of 3 months is enough to distinguish SVO from acute posterior vitreous detachment (PVD) 'floaters', which generally settle in this time period, and indicates the persistence of these vitreous opacities as well as the failure of patients to adapt to them.

We suggest the classification of SVO into two main categories; SVO without PVD, commonly present in young myopes, and SVO with PVD. This classification may have implications both in pathogenesis and in their treatment.

SVO can also be divided into primary, including those associated with PVD with or without retinal breaks, or secondary to other ocular diseases. Secondary SVO are seen in asteroid hyalosis, vitreous haemorrhage, retinal tears or detachment, uveitis, or in association with systemic diseases like nonHodgkin's lymphoma and amyloidosis. ${ }^{2}$ For the purposes of this review, SVO refers to primary SVO.

Various treatment options have been described for SVO including Nd-Yag laser vitreolysis; ${ }^{3}$ cataract surgery combined with deep anterior vitrectomy; ${ }^{4}$ and pars plana vitrectomy (PPV). ${ }^{2,5}$ Because patients with SVO usually have no loss of visual acuity using standard measures such as LogMAR or Snellen charts, the treatment is predominantly patient-driven with little in the way of objective outcome measures except patient-reported outcomes. Hence treatment of the condition with its associated risks remains controversial. ${ }^{6}$ In this manuscript, we aim to review the epidemiology, pathogenesis, clinical features, including impact on the quality of life, and the various treatment options available for SVO, with a special emphasis on safety, efficacy, and patient outcomes following vitrectomy for this condition.
${ }^{1}$ Manchester Royal Eye Hospital, Central Manchester University Hospitals NHS Foundation Trust, Manchester Academic Health Science Centre, Manchester, UK

${ }^{2}$ Centre for

Ophthalmology and Vision Science, Institute of Human Development, University of Manchester, Manchester, UK

\section{${ }^{3}$ Humanitas Clinical Research Center, Rozzano-Milan, Italy \\ Correspondence: N Patton, Manchester Royal Eye Hospital, Central Manchester University Hospitals NHS Foundation Trust, Manchester Academic Health Science Centre, Oxford Road, M13 9WH Manchester, UK Tel: +44 (0)161 2761234; Fax: +44 (0)161 2726618. E-mail: niall.patton@cmft. nhs.uk}

Received: 9 July 2015 Accepted in revised form: 23 November 2015 Published online: 4 March 2016 


\section{Vitreous structure}

The vitreous is a highly hydrated gel-like structure (>98\% water) that is normally acellular, apart from a few cells called hyalocytes in the vitreous cortex. ${ }^{7}$ The gel state of the vitreous is maintained by a network of long, thin collagen fibrils that are $\sim 15 \mathrm{~nm}$ in diameter. The concentration of these collagen fibrils is highest in the vitreous base and decreases posteriorly, but then increases in the cortical layer of the vitreous, which is attached to the inner surface of the retina. Filling the space between the collagen fibrils is a network of hyaluronan; this glycosaminoglycan (polysaccharide) attracts water and generates a swelling pressure that inflates the gel.

The collagen fibrils are composed of collagen types II, $\mathrm{V} / \mathrm{XI}$ and IX. Collagen types II and V/XI form the core of the rope-like collagen fibrils, whereas type IX collagen molecules are regularly distributed along the fibril surfaces. ${ }^{7}$ The type IX collagen has chondroitin sulfate glycosaminoglycan chains attached to it which extend away from the fibril surfaces and space apart the collagen fibrils, thereby preventing fibril aggregation (Figure 1). ${ }^{8}$ The individual collagen fibrils are organised into small bundles, and interconnections between these bundles allow the formation of an extended network that maintains the gel state. ${ }^{9}$

\section{Pathogenesis of SVO}

On the basis of pathogenesis, SVO can be divided into two main categories, SVO without PVD and SVO with PVD.

\section{SVO without PVD}

During ageing the vitreous progressively liquefies and pockets of liquid form in the gel (syneresis). ${ }^{10}$ In an adult eye, about $20 \%$ of vitreous is liquid, then after the age of 40 years there is increasing liquefaction so that by 80 to 90 years of age more than half of vitreous is liquid. ${ }^{11}$ These changes are accelerated in myopia. ${ }^{12}$ The liquefaction is caused by aggregation of the collagen fibrils which leads to a redistribution of the fibrils with the aggregates becoming concentrated in some areas of the gel, but other parts of the vitreous cavity becoming devoid of collagen fibrils and thereby converted into liquid compartments. The aggregation of collagen is a result of the fibrils losing the type IX collagen and hence the chondroitin sulfate chains from their surfaces; as the fibrils are no longer spaced apart they come into contact and because collagen is sticky they fuse together (Figure 1). ${ }^{8}$ These aggregates, when sufficiently large, can be visible as SVOs.

\section{SVO with PVD}

Vitreous liquefaction, in conjunction with age-related weakening of the postbasal vitreoretinal adhesion, results in PVD. Post mortem studies found PVD to be present in $27 \%$ of eyes by the seventh decade and $63 \%$ by the eighth decade of life. ${ }^{13}$ During PVD there is separation of the postbasal vitreous from the inner surface of the retina. The plane of cleavage is most usually at the interface between the cortical vitreous and the inner limiting lamina (ILL, a basement membrane on the inner surface of the retina). However, splitting can also occur within the cortical vitreous or within the ILL, resulting in basement

\section{a}

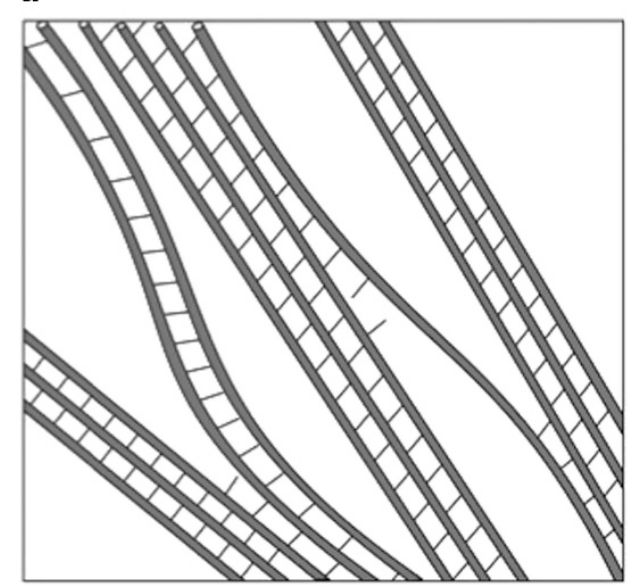

b

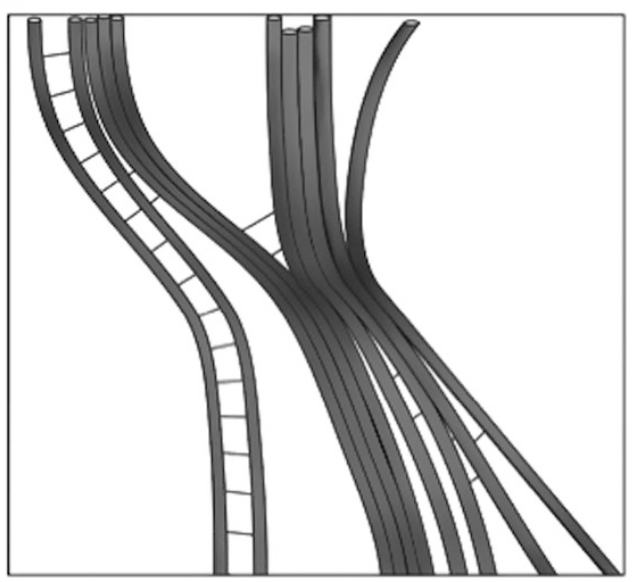

Figure 1 The collagen fibrillar network of the vitreous and ageing changes. (a) The collagen fibrils (thick grey lines) form an extended network by being organised into small bundles that are interconnected by collagen fibrils running from one bundle to another. Within each bundle the collagen fibrils are both connected together and spaced apart by the chondroitin sulfate chains of type IX collagen (thin black lines). (b) With ageing there is a loss of type IX collagen from the fibril surfaces. The loss of the type IX collagen chondroitin sulfate chains from the fibril surfaces combined with an increased surface exposure of type II collagen results in collagen fibrillar aggregation. Reprinted by permission from Macmillan Publishers Ltd: Eye; 2008;22:1214-1222. 
membrane components being present within the detached posterior hyaloid membrane (cortical vitreous gel). ${ }^{14}$ Aggregates of vitreous collagen or fragments of the ILL in the posterior hyaloid membrane may be seen as SVO when this is no longer attached to the inner surface of the retina. During PVD a ring of fibrous tissue becomes detached from the optic nerve and is frequently visible on the posterior hyaloid membrane; this structure, called the 'Weiss ring', is frequently visible seen as a large 'comma' or 'c-shaped' SVO. Over time the residual gel collapses further and this results in the posterior hyaloid membrane moving anteriorly and inferiorly, and the floaters becoming less visible.

\section{Epidemiology}

Schulz-Key et $a l^{5}$ have estimated the incidence of SVO as $3.1 / 100000$ per year based on their cohort of 80 patients who presented to a tertiary centre in Sweden over a 9-year period and required PPV. The total incidence of all patients with SVO including those with visual disability which did not end up having surgery is unclear from this study.

Despite being a common symptom, only one study has looked at the distribution of SVO in the general population. ${ }^{15}$ Webb et $a l^{15}$ have looked at the prevalence of floaters in the community using a sample from smartphone users. Out of a total of 603 individuals who completed this electronic survey, 76\% reported floaters and $33 \%$ found these to be causing visual impairment. Myopes were 3.5 times more likely to report SVO. This study focused mostly on younger age group with $<5 \%$ being above the age of 50 years. There may be recruitment bias in calculating prevalence here in that those with less SVO are more likely to read and take electronic surveys. Also those who are more worried about their health are more likely to participate in these questionnaires. Still this is one of the few studies in the literature that attempts to quantify the prevalence of floaters in the general population.

\section{Natural history}

Many patients experience floaters, but generally the symptoms are not troublesome. The vitreous opacities are mobile and move out of the visual axis, especially after a PVD when they move anteriorly causing the symptoms to diminish. ${ }^{5}$ Serpetopoulas et $a l^{16}$ have mathematically shown that the shadow of a vitreous opacity on the retina is determined by the diameter of the opacity, its distance from the retina and the overall distance between the pupillary plane and the retina. As these vitreous opacities move forward, over time their conic shadow no longer reaches the retina and the patient does not perceive them or only sees them intermittently.

Hence, if the patient is acutely symptomatic with floaters, generally at the onset of PVD, in most cases the initial symptoms are transient as the patients learn to 'live with them', and with time they become manageable or minimal.

However, in a small group of patients floaters have a significant impact on the quality of life. This is especially true for myopes where liquefaction of vitreous starts early and progresses with age and axial elongation. ${ }^{17}$ This process causes aggregation of collagen fibrils in turn leading to SVO initially without PVD and then over time with PVD.

\section{Impact of SVO on vision-related quality of life}

In young patients without PVD, collagen fibrils aggregate and move in lacunae giving rise to vitreous opacities.

Once vitreous opacities are formed, they cause an area of uniform partial illumination or penumbra on the retina behind them. The symptoms of floaters such as perceiving 'muscae volitantes' (Latin: flying flies), cloud or smoke depend on this area of penumbra, which in turn is dependent on the diameter of the vitreous opacity, its distance from the retina and the distance of the pupillary plane from the retina. ${ }^{16}$ Recently spectral domain OCT has demonstrated in vivo this area of shadowing behind a vitreous opacity as a 'floater scotoma'. ${ }^{18}$

In patients without PVD, floaters tend to be less in number and more linear as compared with those with PVD. ${ }^{11,19}$

PVD is accompanied by a sharp increase in floaters, but after the acute phase, the symptoms settle down, partly because of the forward movement of cortical vitreous away from the macula and partly owing to adaptation. 5,16 However, a subset of patients continue to have quite troublesome floaters despite enjoying good visual acuity.

Wagle et $a l^{1}$ have looked at the impact of floaters on the health-related quality of life in a cohort of 266 patients using a standardised utility value questionnaire, and concluded that symptomatic degenerative vitreous floaters had a negative impact on the health-related quality of life. The cohort studied by this group on an average was willing to take a $7 \%$ risk of blindness to get rid of SVO, and this risk was comparable to that reported by patients with diabetic retinopathy and age-related macular degeneration. They also found that younger symptomatic patients, who are more economically active, were more willing to take a higher risk of blindness than older patients. One limitation of this study is that more than half of the patients included in this study had acuteonset floaters of $<4$ weeks' duration. Although the authors concluded that health-related utility values were 
similar in these patients when compared with those having chronic floaters, it is important to note that most of the patients with acute SVO become less symptomatic with time. ${ }^{5,16}$ Hence utility values in many of these patients will be less significant when carried out months later, as only a small proportion of these acutely symptomatic patients will go on to become chronically symptomatic; hence the need for studies looking at cost-utility analysis in chronic SVO. Furthermore, this study only looks at broad health indices and not on the impact of floaters on vision-specific tasks. In addition, the study is from Singapore where myopia, often associated with SVO, has a high prevalence rate. ${ }^{20}$

de Nie et $a l^{21}$ examined the effect of 'bothersome' vitreous floaters on the quality of life by looking at visiondependant tasks and found that more than two-third of the patients had moderate or extreme difficulty in reading small print as well as driving at night. They concluded that the functional consequences of chronic primary floaters may be just as problematic for some individuals as other well-established ocular conditions that are viewed upon as having more impact on visual functioning, such as cataract or a macular epiretinal membrane, despite patients with SVO having good visual acuity.

\section{SVO: a psychological perspective}

It has been postulated in a few studies that patients with particular personality traits are more likely to consider SVO as a health problem severe enough to justify treatment by any means including surgery. $2,5,22$ Two different hypotheses have been put forward to explain this.

Schiff et $a l^{2}$ believed that patients who are more professionally successful and intelligent notice floaters more and have increased desire to have them treated. Their small series of five patients included an ambassador, a history professor and a senior research engineer. Another study by Roth et $a l^{22}$ have identified a correlation between subjective distress caused by SVO and level of education.

Alternatively Schulz-Key et $a l^{5}$ have suggested that because vitreoretinal surgeons are inherently reluctant to operate on patients with SVO who have excellent visual acuity, only those patients get selected who are used to 'getting their own way' and who pursue their interests more effectively. This hypothesis has been supported by Mason et $a^{23}$ who concluded that patients with SVO often get frustrated and disappointed as ophthalmologists fail to address the health concern which is affecting their quality of life. Only patients with more active lifestyle who read and write more frequently and who are determined to get rid of their symptoms present to the retinal clinics more often to pursue surgery regardless of their profession. Hence there is a selection bias in patients undergoing PPV for SVO. The authors recommended that ophthalmologists should be increasingly sensitive to the problem of SVO causing significant visual distress in a group of patients.

All these studies have suggested certain potential personality traits in patients with SVO, but at present there is no definitive evidence regarding the psychology of this cohort of patients.

\section{Non-observational treatment}

\section{The role of PPV in the management of SVO}

Since its inception nearly 40 years ago by Machemer et al, ${ }^{24}$ three-port PPV has evolved to become the standard surgical procedure for a variety of retinal pathologies, including retinal detachment (RD), macular hole, epiretinal membrane, and proliferative diabetic retinopathy. ${ }^{28}$ As instrumentation and surgeon experience with PPV have improved particularly with the advent of transconjunctival sutureless vitrectomy, the indications for vitrectomy have also increased.

PPV is increasingly finding favour as the most definitive therapeutic intervention for SVO. Wilkinson, ${ }^{29}$ in an editorial in American Journal of Ophthalmology as recent as 2011, wrote that after vitrectomy for floaters both visual and anatomical outcomes are excellent. However, in the same article, the author states that the patient and surgeon must ultimately confront the question of 'how safe is safe?' or 'does the frequency of complications of vitrectomy for vitreous floaters justify the associated risk?'.

One of the earliest studies on PPV for SVO was by Schiff et $a l^{2}$ in 2000 who looked at patients with visually disabling vitreous opacities where vitrectomy was carried out if the symptoms persisted for $>12$ months. $^{2}$

All patients in this cohort were either pseudophakic or aphakic to avoid the progression of lenticular cataract seen in phakic patients following vitrectomy. Postoperatively the visual acuity improved or remained equal to pre-operative acuity in all patients, and no surgical complications were seen. Assessment of the quality of life using National Eye Institute Visual Function Questionnaire-39 (NEI VFQ-39) showed that general vision, near and distance activities, mental health, and peripheral vision were much better following PPV for floaters. Patients also reported an increased reading function and increased ability to drive, walk, and play sports following surgery. The authors felt that floaters were more likely to affect professionally successful, active, and intelligent individuals who were observant and specific in their symptom description. This study had a 
few weaknesses such as being limited to only aphakic and pseudophakic patients, its retrospective nature and the fact that only six eyes of five patients were included. Also they only looked at SVO with PVD, and all patients were $>50$ years of age.

In 2002 Delaney et $a l^{30}$ presented their results of vitrectomy for floaters on 15 patients, 11 of whom had previously been unsuccessfully treated with laser vitreolysis. There was complete resolution of symptoms in 14 patients with one patient continuing to have a recurrent post-operative anterior floater, most likely owing to the residual anterior vitreous. One patient developed a post-vitrectomy RD that was successfully repaired subsequently, and one patient had progression of lenticular sclerosis. Again this study was retrospective in nature and only looked at floaters with PVD. In addition, PPV was mostly carried out for patients who previously had unsuccessful YAG vitreolysis and therefore its results may not be representative of vitrectomy as primary treatment for SVO.

Schulz-Key et al ${ }^{5}$ evaluated long-term results of PPV for floaters in their study of 73 cases with an average follow-up time of 37 months by looking at patientreported outcomes with the help of a questionnaire developed for this study. ${ }^{5}$ Patient satisfaction was achieved in $88 \%$ of patients. The commonest complication was cataract formation with $60 \%$ of phakic patients undergoing cataract surgery during follow-up. One RD occurred immediately post-operatively $(1.3 \%)$ and another four eyes developed RD during long-term followup 24-44 months after PPV (5.5\% of cases). The authors believed that the higher late risk of RD might have been partly owing to missed sclerotomy-related entry-site breaks and partly because of the higher incidence of pseudophakic patients in their group. However, it may also be because the surgeons only performed core vitrectomy in most cases with the residual vitreous causing late-onset retinal breaks and RD.

Stoffelns et $a l^{31}$ have reported a series on SVO where PPV was just limited to pseudophakic patients. Forty-one eyes of 32 patients were operated on over a 10-year period, with 31 patients being very satisfied with the procedure. The visual acuity was equal or better than pre-operative acuity in $95 \%$ of the patients. Only one patient developed RD post-operatively.

More recently, small-gauge PPV for SVO has been described. ${ }^{32,33}$ A retrospective study of 8 patients looked at the efficacy and safety of 25-gauge PPV for floaters in a selected group of myopic, pseudophakic patients. ${ }^{32}$ No complications were observed in this group, and 37.5\% improved one or more lines of visual acuity. Healthrelated quality of life measured with the NEI VFQ-39 showed that the most frequent improvement (83.3\%) was the subjective perception of their general eyesight, the performance of tasks requiring greater fixation and the relationship with people outside their home. The study though was retrospective with small numbers.

Mura et $a l^{33}$ have tried to quantify the effect of floaters on the quality of life by looking at the scattering of light caused by them (straylight) and improvement of straylight values following vitrectomy. In their study of 39 patients all of whom had 25-gauge procedure, PPV caused a statistically significant decrease in straylight. Straylight values improved in 38 of 39 cases (97\%), and the mean pre-operative straylight value was $1.54 \mathrm{log}$ \pm 0.33 and this decreased to a value of $1.26 \pm 0.20$ after vitrectomy ( $P<0.001$; Wilcoxon's signed-rank test).

One of the largest studies on the subject of PPV for SVO has been by Tan et $a l^{6}$ who analysed the safety of vitrectomy for floaters by looking at the incidence of iatrogenic retinal breaks and post-vitrectomy RD in their cohort of 116 consecutive patients. This study included both 20-gauge (29 cases) and 25-gauge (87 cases) and found iatrogenic retinal breaks in $16.4 \%$ of operations and $\mathrm{RD}$ in $2.5 \%$ of cases with no secondary ocular pathology. As expected, iatrogenic retinal breaks were observed in over $30 \%$ of the cases requiring PVD induction and in $<12 \%$ of those in which active PVD induction was not performed, the difference being statistically significant. Cataract occurred in $50 \%$ of phakic eyes. The mean visual acuity improved from 0.20 to 0.13 LogMAR. In contrast to other studies, the authors felt that the risk profile of PPV for floaters was significant and was comparable with vitrectomy for other elective indications, and warned against the view of vitrectomy for SVO as a 'straightforward, low-risk procedure'. However, there are some limitations of this study. Like most of the literature on floaters, it is retrospective in nature. The study included both 20- and 25-gauge procedures adding a variable to the equation. Also they did not find any statistical difference in the incidence of retinal breaks between the two groups, which is in contrast to some major studies showing that the incidence of retinal breaks is significantly less in transconjunctival sutureless vitrectomy as compared with 20-gauge procedures. ${ }^{34-35}$ In a large study, Jalil et $a l^{36}$ have shown that the incidence of total anterior iatrogenic breaks was $16.7 \%$ for $20-\mathrm{G}$ PPV and 7.8\% for 23-G PPV, the difference being highly statistically significant.

de Nie et $a l^{21}$ have looked at 110 eyes that underwent PPV for floaters, $51.8 \%$ being 20 -gauge and $48.2 \%$ being 23 -gauge. They found RD in $10.9 \%$ of cases, $4.5 \%$ within 3 months of the surgery and $6.4 \%$ later on. In their group of phakic eyes, cataract surgery in the follow-up period was seen in $75 \%$ of those with pre-vitrectomy mild lens opacities and $38 \%$ of those with pre-surgery clear lenses. Patient quality of life following PPV was assessed using a modification of NEI VFQ-25 questionnaire. Eighty-five 
per cent of patients were satisfied after surgery, $6 \%$ were neutral, and about $9 \%$ were dissatisfied. There was an overall improvement in visual function; $71 \%$ had difficulty in reading small print, which markedly improved after surgery; $62 \%$ had difficulties with computer work which reduced to about $17 \%$ postvitrectomy; driving at night was a problem in $85 \%$ of patients of which $86 \%$ improved after surgery. About $87 \%$ of patients would recommend vitrectomy for floaters to a friend with comparable complaints. Again the study was retrospective and included both 20- and 23-gauge vitrectomies. Also the incidence of RD (10.9\%) post-PPV was much higher than most other reports in the literature. ${ }^{36-38}$ However, the authors have admitted that they did not perform a thorough internal search with scleral indentation routinely at the end of the procedure, which may have resulted in missed retinal breaks leading to RD subsequently. This study included some RDs, which occurred following cataract surgery long after PPV, which may have skewed the results as well.

Floaters-only-vitrectomy. Recently Sebag et $a^{39}$ have published a prospective study on PPV for floaters. They performed 25-gauge PPV for symptomatic floaters of at least 24 months' duration in 76 eyes, and evaluated the efficacy in 16 patients using contrast sensitivity function and subjective visual function using NEI VFQ. In this study the authors performed Floaters-only-Vitrectomy (FOV), which is defined as vitrectomy without PVD induction if PVD is not present at the start of surgery to theoretically reduce the risk of iatrogenic retinal breaks. In addition, anterior vitreous was left in situ to protect the lens against free oxygen radicals and reduce post-PPV cataract formation. It was concluded that PPV for floaters is highly efficacious, with contrast sensitivity that was diminished by $67 \%$ in patients with floaters normalising in all cases up to 9 months post-surgery, and the visual function improving by $29.2 \%$. This technique was found to be highly safe with no case of post-PPV retinal breaks or $\mathrm{RD}$, and only $23.5 \%$ developing cataract at an average of 15 months post-operatively. The mean age of this subgroup was 60.5 years (range 53-66 years). The main risk with FOV is that not only does the absence of PVD induction intra-operatively leave the risk of vitreous detaching later and leading to post-PPV retinal breaks and $\mathrm{RD}$, but also causing the recurrence of symptomatic floaters. The authors have acknowledged themselves that 1 out of 76 eyes in their cohort developed symptomatic floaters during the onset of PVD later requiring a repeat vitrectomy.

Mason et $a^{23}$ have recently published the largest series of patients to date on the subject of PPV for SVO. ${ }^{23}$ This retrospective study presented the results of $25-\mathrm{G}$ PPV on
168 eyes of 143 consecutive patients with persistent symptomatic floaters, of which 88 eyes had SVO with PVD and 80 eyes had SVO without PVD. In the subgroup with no PVD, the authors performed FOV in 68 eyes and PVD induction was carried out in 12 eyes. Overall the mean Snellen visual acuity in this study improved from $20 / 40$ pre-operatively to $20 / 25$ post-operatively. Iatrogenic retinal breaks were present in $7.1 \%$ of the eyes. Surprisingly PVD induction was not considered a risk factor for retinal break formation in contrast to previous literature. 6,36 Again anterior hyaloid was left in situ, except in patients with retinal break formation, and only $22.5 \%$ of phakic patients developed a visually significant cataract requiring phacoemulsification during a mean follow-up of 18 months. This rate is less than that reported in literature (38-60\%). 5,6,21 Also in this study the authors have not given the mean age of the phakic group, although the mean age of all patients in their study was 63 years (range 41-87 years). A quality of life survey in this group using a modified nine-QOL questionnaire showed that $96 \%$ of patients were satisfied with the surgery, with $94 \%$ calling it a complete success. Limitations of this study include its retrospective nature, limited patient population and difficulty in establishing the presence or absence of pre-operative PVD. The surgical technique was not standard with most of the patients having FOV and a small subset having PVD induction leading to a confounding factor. Finally, quality of life was assessed using a telephonic survey months after the surgery which may have resulted in a recall bias. However, it is the largest case series to date and focuses only on small-gauge vitrectomy.

FOV clearly has reputed advantages in that the risks of cataract formation and retinal breaks leading to post-PPV $\mathrm{RD}$ are minimised. However, any intervention in the vitreous is highly likely to lead to a breakdown of collagen structure and change the dynamics of vitreous. A simple procedure of an intravitreal injection has previously been reported as increasing the induction of PVD. ${ }^{40}$ In a sense, FOV resembles senile vitreous liquefaction by creating lacunae in the vitreous. This in turn may potentially lead to alterations in cortical vitreous eventually leading to a PVD sooner in life than would have happened otherwise. This may consequently result in recurrence of floaters as seen in a case in the study by Sebag et al, ${ }^{39}$ but may also run the risk of retinal breaks and RD. Hence the theoretical advantages of FOV of reduced cataract formation and RD should be balanced carefully against the potential 'mortgage' a limited vitrectomy places on the status of a non-PVD healthy eye.

The most serious risk of intraocular surgery is endophthalmitis, and in the context of vitrectomy for floaters, this is of utmost importance as patients 
invariably have excellent visual acuity before surgery. Recently there have been two reports of endophthalmitis following PPV for SVO. Henry et al ${ }^{41}$ presented a case of Staphylococcus caprae endophthalmitis following 20-G vitrectomy for vitreous floaters, which was treated with vitreous tap and intravitreal antibiotics. The patient had a pre-PPV visual acuity of $6 / 9$, which worsened after the endophthalmitis to $6 / 24$ at 9 months partially limited by the nuclear sclerotic cataract. Similarly, Park et al ${ }^{42}$ have published a large, prospective nation-wide study looking at endophthalmitis after PPV in UK. In their series, 28 out of a total of 48433 eyes ( 1 in 1730) undergoing vitrectomy developed endophthalmitis. Two of the patients developed this complication after surgery for SVO, with one patient regaining a visual acuity of $6 / 9$ at 6 months, whilst the other developed $\mathrm{CMO}$ and ended up with a visual acuity of 6/96.

The two studies mentioned above by Sebag et $a l^{39}$ and Mason et $a l^{23}$ continue the trend of recently published reports with large patient numbers on PPV for SVO indicating that with the advent of small-gauge vitrectomy, the threshold for surgery in these patients may be going down. ${ }^{23,39}$ Henry et al ${ }^{41}$ have commented on these two studies in a recent editorial and remarked that it is surprising that a significant number of patients with SVO have presented to these centres with visual disability to the extent that PPV was warranted. ${ }^{43}$ They have cautioned against trivialising PPV for SVO, and once again stressed the importance of informed consent regarding the risks of PPV in this group of patients.

Alternatively Wa and Sebag ${ }^{44}$ have argued in another editorial that patients perceive SVO as a significant health problem, and minimally invasive small-gauge PPV appears safe and effective to treat this condition.

\section{Summary of various studies on PPV for SVO.}

Clinical implications of SVO: Schiff et al $\mathrm{l}^{2}$ performed vitrectomy for floaters, which were persistent, visually disabling, affected job function, and made patients blink or turn their head to see clearly. In the study by Delaney et al, $3068 \%$ of patients had floaters for $>6$ months with most marked symptoms generally on reading. In the studies by Schulz-Key et al, ${ }^{5}$ Martinez-Sanz et al, ${ }^{32}$ Mura $e t a l, 33$ and Tan $e t a l^{6}$ vitrectomy was only carried out where visually disabling floaters persisted for $>6$ months. de Nie $e t a^{21}$ analysed the functional consequences of SVO in more detail. In their group of patients requiring vitrectomy, $65 \%$ of patients were bothered by floaters all the time, $71 \%$ had moderateto-extreme difficulties reading small print, $62.6 \%$ had difficulties with computer work, and $84.7 \%$ had difficulties with night driving because of floaters. Sebag et $a l^{39}$ concluded that floaters reduced the contrast sensitivity function by $67.4 \%$ owing to the presumed light-scattering effects. In the group reported by Mason et al, ${ }^{23} 73 \%$ of patients described their daily severity of symptoms as 'severe' or 'very severe', $50 \%$ had problems with reading, 30\% with driving, $12 \%$ with occupational tasks, and $8 \%$ with leisure activities.

Efficacy of vitrectomy for SVO: In the study by Schiff et $a l^{2}$ all five patients reported complete resolution of symptoms, increased reading ability, and increased ability to play sports following PPV for SVO. In the study by Delaney et al, ${ }^{30}$ there was complete resolution of symptoms in $93.3 \%$ of patients. Schulz-Key et al ${ }^{5}$ reported patient satisfaction in $88 \%$ of patients with $73 \%$ noticing improvement in vision after surgery. Stoffelns et $a l^{31}$ had patient satisfaction in 31 out of 32 patients (96.9\%). Martinez-Sanz et al ${ }^{32}$ reported $100 \%$ satisfaction with $25-G$ PPV for floaters. de Nie $e t a^{21}$ in their large group of 110 patients had a patient satisfaction of $85 \%$, with $84 \%$ completely cured of SVO. However, 9.3\% were

dissatisfied, with $5.6 \%$ of these patients having a serious complication, which resulted in permanent visual loss.

In the FOV studies, Sebag et al ${ }^{39}$ showed complete resolution of symptoms in 15 out of 16 eyes (93.4\%) with contrast sensitivity improving in $100 \%$ of cases. Mason et $a l^{23}$ had a satisfaction of $96 \%$ in their study with $94 \%$ calling their experience a complete success.

Safety of vitrectomy for SVO: The two major concerns after PPV for floaters are cataract formation in phakic eyes and post-vitrectomy RD.

In series where full vitrectomy was carried out for floaters, Tan $e t a l^{6}$ reported the incidence of cataract at $50 \%$ over a mean follow-up of 10.1 months. This is comparable to the incidence of $60 \%$ given by Schulz-Key et $a l^{5}$ over a mean follow-up period of 37 months. In the study by de Nie et al, ${ }^{21}$ of 50 eyes with clear lens before surgery, 19 eyes (38\%) underwent cataract surgery during a period of 26.4 months. FOV with sparing of anterior vitreous is theoretically more lens friendly and the reported rate of cataract formation is lower at $23.5 \%$ (over 15 months) and $22.5 \%$ (over 18 months) in the two large studies by Sebag et al ${ }^{39}$ and Mason et al. ${ }^{23}$

There is a great variation in literature in the incidence of $\mathrm{RD}$ post-PPV for $\mathrm{SVO}$ with figures ranging from $0,{ }^{2,32},{ }^{31}$ $2.5,6.7,30$ and $6.8 \%,{ }^{5}$ to as high as $10.9 \% .{ }^{21}$ FOV does not involve PVD induction with its associated risks of retinal breaks and post-PPV RD. Hence the series by both Sebag et $a l^{39}$ and Mason et $a l^{23}$ do not have a single case of RD in their respective cohorts of 76 and 168 cases respectively.

Other complications following PPV for SVO include CMO (0.6-5.5\%), ${ }^{5,21,23}$ epiretinal membrane formation $(1.3-3.6 \%),{ }^{6,21,39}$ transient vitreous haemorrhage $(1.2 \%),{ }^{23}$ glaucoma $(0.9 \%),{ }^{21}$ macular hole $(0.9 \%),{ }^{21}$ and postoperative scotoma $(0.9 \%) .{ }^{21}$ Similarly, there have been 
Table 1 A summary of various studies on PPV for SVO

\begin{tabular}{|c|c|c|}
\hline Studies & Efficacy and patient satisfaction & Complications \\
\hline $\begin{array}{l}\text { Schiff } e t a l^{2} \\
6 \text { cases/20G PPV }\end{array}$ & Resolution of symptoms and satisfaction in $100 \%$ & None \\
\hline Delaney et $a l^{30}$ & Resolution of symptoms in $93.3 \%$ & Cataract $(n=1)$ \\
\hline 15 cases/20G PPV & & $\mathrm{RD}(n=1)$ \\
\hline Schulz-Key et al ${ }^{5}$ & Satisfaction in $88 \%$ & Cataract $(60 \%)$ \\
\hline 73 cases/20G PPV & & $\begin{array}{l}\text { RD }(6.8 \%) \\
\text { CMO }(2.7 \%)\end{array}$ \\
\hline $\begin{array}{l}\text { Stoffelns et al } \\
41 \text { cases } / 20 \mathrm{G} \text { PPV }\end{array}$ & Satisfaction in $97 \%$ & $\mathrm{RD}(2 \%)$ \\
\hline Martínez-Sanz et al ${ }^{32}$ & Satisfaction in $100 \%$ & None \\
\hline 8 cases $/ 25 G$ PPV & Improvement in subjective perception of vision $83.3 \%$ & \\
\hline $\begin{array}{l}\text { Mura et al }{ }^{33} \\
39 \text { cases } / 25 \mathrm{G} \text { PPV }\end{array}$ & Straylight value improvement in $97 \%$ & Not mentioned \\
\hline Tan et al & Mean VA improvement from 0.20 to & Iatrogenic retinal breaks (16.4\%) \\
\hline 116 cases $/ 20+25 \mathrm{G} P P V$ & $0.13 \operatorname{LogMAR}(P<0.001)$ & $\begin{array}{l}\text { RD }(2.5 \%) \\
\text { Cataract }(50 \%) \\
\text { Macular pucker }(1.7 \%)\end{array}$ \\
\hline de Nie et $a l^{21}$ & Satisfaction in $85 \%$ & Cataract $(38 \%)$ \\
\hline 110 cases $/ 20+23-G$ PPV & $\begin{array}{l}\text { Complete resolution of symptoms in } 84 \% \text { and } \\
\text { partial resolution in } 9.3 \%\end{array}$ & $\begin{array}{l}\text { RD }(10.9 \%) \\
\text { CMO }(5.5 \%) \\
\text { ERM }(3.6 \%) \\
\text { Glaucoma, macular hole and } \\
\text { postoperative scotoma }(0.9 \% \text { each })\end{array}$ \\
\hline Sebag et $a l^{39}$ & Contrast sensitivity improvement in $100 \%$ & Cataract $(23.5 \%)$ \\
\hline 76 cases $/ 25 G$ PPV & Visual function improvement by $29.2 \%$ & Macular pucker (1.3\%) \\
\hline Mason et $a l^{23}$ & Mean Snellen VA improvement from $20 / 40$ to $20 / 25$ & Iatrogenic retina breaks $(7.1 \%)$ \\
\hline 168 cases/25G PPV & Satisfaction in $96 \%$ & $\begin{array}{l}\text { Cataract }(22.5 \%) \\
\text { CMO }(0.6 \%) \\
\text { Transient vitreous haemorrhage }(1.2 \%)\end{array}$ \\
\hline
\end{tabular}

Abbreviations: CMO, cystoid macular oedema; ERM, epiretinal membrane; RD, retinal detachment; VA, visual acuity.

two separate reports of endophtalmitis following PPV for floaters as well. ${ }^{41,42}$

Table 1 summarises all the major studies on PPV for SVO.

\section{Alternative options}

Nd:YAG laser vitreolysis. Nd-YAG laser viteolysis is an alternative option, described for the treatment of SVO. 3,30,45-47 Laser vitreolysis reputedly aims to reduce the volume of a floater by disintegrating it down into smaller fragments or alternatively by cutting the small vitreal strands on which the opacity is suspended within the vitreous cavity, allowing it theoretically to 'dislodge' and clear from the optical axis.

The original study on YAG vitreolysis for SVO by Tsai et $a^{45}$ in 1993 reported no complications and complete resolution of symptoms in all 15 cases. The authors identified the causal SVO using a direct ophthalmoscope, and used the flat fundus lens of the Goldmann threemirror lens in conjunction with a Q-switch YAG laser. The power was set between 5 and $10 \mathrm{~mJ}$ with one pulse per burst. The energy used depended on the size of the vitreous opacity and varied from 71 to $742 \mathrm{~mJ}$ with an average of $286 \mathrm{~mJ}$. There are many limitations of this study and technique. First, direct ophthalmoscopy was used to identify the causal vitreous opacity, and the authors felt most of the problematic vitreous opacities were centrally located and less than three in number. Also the opacities had to be at least $4 \mathrm{~mm}$ away from the retina to avoid laser-induced retinal damage. Hence, if the SVO are greater in number and/or closer to the retina, this technique may not alleviate the symptoms, thus putting into doubt the efficacy of this technique. Then a significant amount of energy was used in the posterior segment, and its safety was based on a fluorescein angiography test carried out on the third day, which was normal in all cases. However, there are a lot of reported complications with using Nd-YAG laser in vitreous including cataract formation, retinal and choroidal haemorrhage, retinal breaks, and damage to retinal pigment epithelium. ${ }^{46-50}$ All the patients in this study had a follow-up of 12 months, which may not be enough to truly determine the safety of this technique.

Little et $a l^{51}$ reported their experience of $\mathrm{Nd}-\mathrm{YAG}$ laser for various posterior segment diseases in 59 eyes. Of these 25 eyes had SVO, and Nd-YAG laser was only effective in 14. Complications reported in this series included focal 
lens opacities, retinal haemorrhages, retinal breaks, and RD.

The subsequent work by Delaney et $a l^{30}$ was even less encouraging; the authors concluded that intravitreal Nd-YAG vitreolysis relieved symptoms in only a third of patients and the clinical improvement was only moderate in degree, subjectively being graded at no greater than $50 \%$ by $93.3 \%$ of patients. ${ }^{30}$ Moreover, in no patient was there a complete resolution of symptoms. Also laser treatment led to worsening of symptoms in $7.7 \%$ of their patients.

There has been a recent report of a risk of refractory open-angle glaucoma following Nd-YAG vitreolysis of vitreous floaters. ${ }^{52}$ Cowan et al $l^{52}$ have reported on 3 eyes of 2 patients who presented with an intraocular pressure of $>40 \mathrm{~mm} \mathrm{Hg}$ at varying intervals ( 1 week to 8 months) after this procedure. Initially all eyes were managed medically with two of them requiring selective laser trabeculoplasty and two needing glaucoma-drainage surgery with trabectome before intraocular pressure stabilised. This risk was not linked to inflammation or steroid use. The authors hypothesised that vitreous micro-debris or macrophages laden with vitreous material may have migrated anteriorly and blocked the trabecular meshwork. Intraocular pressure rise following laser vitreolysis has also been reported by Little et al, ${ }^{51}$ but it has mostly been for eyes with vitreous strands to cataract wounds and the spike of pressure has been temporary. A protracted and chronic rise in intraocular pressure presumed to be owing to decrease in outflow facility of the trabecular meshwork has not been reported by the few other studies on this subject, and this risk may need further investigation.

Hence to summarise, there is very little evidencebase for the technique of Nd-YAG vitreolysis for SVO in the literature, and, as discussed, the results and complications reported in the few studies vary considerably.

Phacoemulsification combined with deep anterior vitrectomy. Finally phacoemulsification combined with deep anterior vitrectomy through a posterior curvilinear capsulorhexis has also been described for symptomatic floaters. ${ }^{4}$ However, there is only one paper of 10 eyes describing this technique, the major limitation being that this technique is limited to elderly individuals with advancing lens opacities and can only treat floaters in the anterior vitreous. Also cystoid macular oedema was seen post-operatively in 2 of the 10 eyes described in this paper.

\section{Conclusion}

The quality of evidence on the management of floaters is limited, and most of the studies are retrospective in nature. More prospective studies are needed looking at the natural history of floaters as well as comparing the various treatment options available. The term 'symptomatic vitreous opacities' describes this condition better and the classification of SVO based on the presence or absence of PVD has pathogenetic and therapeutic implications. Various studies have concluded that the functional consequences of SVO can be as problematic as other established ocular diseases, and they have a significant adverse impact on quality of life of a small subset of individuals. Identification of these individuals may need vision-related quality of life questionnaires, as visual acuity remains minimally affected. Of all treatment options available, PPV may offer the best solution in alleviating the symptoms of chronic symptomatic floaters albeit with its associated risks. The procedure profile may be safer in patients with established PVD and possibly a shorter operating time is needed. The major concern of PPV in treating floaters appears to be cataract formation and the incidence of post-vitrectomy retinal breaks and RD. With the increasing switch to transconjunctival smallgauge vitrectomy systems and their advantage of reduced risk of iatrogenic retinal breaks, the procedure may become safer to offer especially to pseudophakic patients and those with cataracts requiring combined phacoemulsification and vitrectomy. The most important aspect of the management of floaters remains patient education and patient selection. Eventually the patient should make an informed decision based on whether living with the functional consequences of a non-blinding condition outweighs the option of a highly efficacious but not risk-free procedure.

\section{Conflict of interest}

The authors declare no conflict of interest.

\section{Acknowledgements}

We acknowledge support from Manchester Biomedical Research Centre. We searched the MEDLINE and PubMed database for all articles using the keywords floaters, vitreous opacities and floaters, floaterectomy and vitrectomy. There was no date restriction in the electronic searches for trials. We limited our review to articles published in English. All articles judged to be of interest were included unless they did not contain any pertinent information on the subject under review. The electronic databases were last searched in November 2014.

We manually searched the reference lists of the studies included in the review for additional studies.

We did not handsearch journals or conference proceedings specifically for this review. 


\section{References}

1 Wagle AM, Lim WY, Yap TP, Neelam K, Au Eong KG. Utility values associated with vitreous floaters. $A m \mathrm{~J}$ Ophthalmol 2011; 152: 60-65.

2 Schiff WM, Chang S, Mandava N, Barile GR. Pars plana vitrectomy for persistent, visually significant vitreous opacities. Retina 2000; 20: 591-596.

3 Vandorselaer T, Van De Velde F, Tassignon MJ. Eligibility criteria for Nd-YAG laser treatment of highly symptomatic vitreous floaters. Bull Soc Belge Ophtalmol 2001; (280): 15-19.

4 Mossa F, Delaney YM, Rosen PH, Rahman R. Floaterectomy: combined phacoemulsification and deep anterior vitrectomy. J Cataract Refract Surg 2002; 28: 589-592.

5 Schulz-Key S, Carlsson JO, Crafoord S. Long term follow-up of pars plana vitrectomy for vitreous floaters: complications, outcomes and patient satisfaction. Acta Ophthalmol 2011; 89: 159-165.

6 Tan HS, Mura M, Oberstein L, Heico MB. Safety of vitrectomy for floaters. Am J Ophthalmol 2011; 151: 995-998.

7 Bishop PN. Structural macromolecules and supramolecular organisation of the vitreous gel. Prog Retin Eye Res 2000; 19: 323-344.

8 Bishop PN, Holmes DF, Kadler KE, McLeod D, Bos KJ. Age-related changes on the surface of vitreous collagen fibrils. Invest Ophthalmol Vis Sci 2004; 45: 1041-1046.

9 Bos KJ, Holmes DF, Meadows RS, Kadler KE, McLeod D, Bishop PN. Collagen fibril organisation in mammalian vitreous by freeze etch/rotary shadowing electron microscopy. Micron 2001; 32: 301-306.

10 Le Goff MM, Bishop PN. Adult vitreous structure and postnatal changes. Eye 2008; 22: 1214-1222.

11 Balazs EA, Denlinger JL. Aging changes in the vitreousIn: Aging and Human Visual Function. Alan R. Liss Inc.: New York, NY, USA, 1982; 45-57.

12 McLeod D, Leaver PK. Trampolines and triangles-the surgical pathology of the vitreous. Trans Ophthal Soc UK 1977; 97: 225-231.

13 Foos RY, Wheeler NC. Vitreoretinal juncture. Synchysis senilis and posterior vitreous detachment. Ophthalmology 1982; 89: 1502-1512.

14 Snead MP, Snead DR, Richards AJ, Harrison JB, Poulson AV, Morris $\mathrm{AH}$ et al. Clinical, histological and ultrastructural studies of the posterior hyaloid membrane. Eye 2002; 16: 447-453.

15 Webb BF, Webb JR, Schroeder MC, North CS. Prevalence of vitreous floaters in a community sample of smartphone users. Int J Ophthalmol 2013; 6(3): 402-405.

16 Serpetopoulos CN, Korakitis RA. An optical explanation of the entoptic phenomenon of 'clouds' in posterior vitreous detachment. Ophthalmic Physiol Opt 1998; 18: 446-451.

17 Morita H, Funata M, Tokoro T. A clinical study of the development of posterior vitreous detachment in high myopia. Retina 1995; 15: 117-124.

18 Schwartz SG, Flynn Jr HW , Fisher YL. "Floater scotoma" demonstrated on spectral-domain optical coherence tomography and caused by vitreous opacification. Ophthalmic Surg Lasers Imaging Retina 2013; 44(4): 415-418.

19 Sebag J. The vitreous: Structure, Function and Pathobiology. Springer-Verlag: New York, NY, USA, 1989; 60-61.

20 Wong TY, Foster PJ, Hee J, Ng TP, Tielsch JM, Chew SJ et al. Prevalence and risk factors for refractive errors in adult Chinese in Singapore. Invest Ophthalmol Vis Sci 2000; 41(9): 2486-2494.
21 de Nie KF, Crama N, Tilanus MA, Klevering BJ, Boon CJ. Pars plana vitrectomy for disturbing primary vitreous floaters: clinical outcome and patient satisfaction. Graefes Arch Clin Exp Ophthalmol 2013; 251: 1373-1382.

22 Roth M, Trittibach P, Koerner F, Sarra G. Pars plana vitrectomy for idiopathic vitreous floaters. Klin Monatsbl Augenheilkd 2005; 222: 728-732.

23 Mason JO 3rd, Neimkin MG, Mason JO 4th, Friedman DA, Feist RM, Thomley ML et al. Safety, efficacy, and quality of life following sutureless vitrectomy for symptomatic vitreous floaters. Retina 2014; 34(6): 1055-1061.

24 Machemer R, Buettner H, Norton EW, Parel JM. Vitrectomy: a pars plana approach. Trans Am Acad Ophthalmol Otolaryngol 1971; 75: 813-820.

25 The SPR Study Group. View 2. The case for primary vitrectomy. Br J Ophthalmol 2003; 87: 784-787.

26 Ezra E, Gregor ZJ. Surgery for idiopathic full-thickness macular hole: two-year results of a randomized clinical trial comparing natural history, vitrectomy, and vitrectomy plus autologous serum: Morfields Macular Hole Study Group. Arch Ophthalmol 2004; 122: 224-236.

27 De Bustros S, Thompson JT, Michels RG, Rice TA, Glaser BM. Vitrectomy for idiopathic epiretinal membranes causing macular pucker. Br J Ophthalmol 1988; 72: 692-695.

28 The Diabetic Retinopathy Vitrectomy Study Research Group. Early vitrectomy for severe vitreous hemorrhage in diabetic retinopathy. Two-year results of a randomized trial. Diabetic Retinopathy Vitrectomy Study Report 2. Arch Ophthalmol 1985; 103: 1644-1652.

29 Wilkinson CP. Safety of vitrectomy for floaters-how safe is safe? Am J Ophthalmol 2011; 151: 919-920.

30 Delaney YM, Oyinloye A, Benjamin L. Nd: YAG vitreolysis and pars plana vitrectomy: surgical treatment for vitreous floaters. Eye 2002; 16: 21-26.

31 Stoffelns BM, Vetter J, Keicher A, Mirshahi A. Pars plana vitrectomy for visually disturbing vitreous floaters in pseudophacic eyes. Klin Monbl Augenheilkd 2011; 228(4): 293-297.

32 Martínez-Sanz F, Velarde JI, Casuso P, Fernández-Cotero JN. Surgical solution to vitreous floaters visual problem. Arch Soc Esp Oftalmol 2009; 84: 259-262.

33 Mura M, Engelbrecht LA, de Smet MD, Papadaki TG, van den Berg TJ, Tan HS. Surgery for floaters. Ophthalmology 2011; 118: 1894-1894.

34 Gosse E, Newsom R, Lochhead J. The incidence and distribution of iatrogenic retinal tears in 20-gauge and 23-gauge vitrectomy. Eye 2012; 26: 140-143.

35 Covert DJ, Henry CR, Bhatia SK, Croskrey J, Sanchez CR, Han DP. Intraoperative retinal tear formation and postoperative rhegmatogenous retinal detachment in transconjunctival cannulated vitrectomy systems compared with the standard 20-gauge system. Arch Ophthalmol 2012; 130: $186-189$.

36 Jalil A, Ho WO, Charles S, Dhawahir-Scala F, Patton N. Iatrogenic retinal breaks in $20-\mathrm{G}$ versus $23-\mathrm{G}$ pars plana vitrectomy. Graefes Arch Clin Exp Ophthalmol 2013; 251: 1463-1467.

37 Rizzo S, Belting C, Genovesi-Ebert F, di Bartolo E. Incidence of retinal detachment after small-incision, sutureless pars plana vitrectomy compared with conventional 20-gauge vitrectomy in macular hole and epiretinal membrane surgery. Retina 2010; 30: 1065-1071.

38 Rasouli M, Steed SM, Tennant MT, Rudnisky CJ, Hinz BJ, Greve MD et al. The 1-year incidence of rhegmatogenous 
retinal detachment post 23-gauge pars plana vitrectomy. Can J Ophthalmol 2012; 47: 262-263.

39 Sebag J, Yee KM, Wa CA, Huang LC, Sadun AA. Vitrectomy for floaters: Prospective Efficacy Analyses and Retrospective Safety Profile. Retina 2014; 34(6): 1062.

40 Geck U, Pustolla N, Baraki H, Atili A, Feltgen N, Hoerauf H. Posterior vitreous detachment following intravitreal drug injection. Graefes Arch Clin Exp Ophthalmol 2013; 251(7): 1691-1695.

41 Henry CR, Schwartz SG, Flynn HW Jr. Endophthalmitis following pars plana vitrectomy for vitreous floaters. Clin Ophthalmol 2014; 8: 1649-1653.

42 Park JC, Ramasamy B, Shaw S, Prasad S, Ling RH. A prospective and nationwide study investigating endophthalmitis following pars plana vitrectomy: incidence and risk factors. Br J Ophthalmol 2014; 98(4): 529-533.

43 Henry CR, Smiddy WE, Flynn HW Jr. Pars plana vitrectomy for vitreous floaters: is there such a thing as minimally invasive vitreoretinal surgery? Retina 2014; 34(6): 1043-1045.

44 Wa C, Sebag J. Safety of vitrectomy for floaters. Am J Ophthalmol 2011; 152(6): 1077.
45 Tsai WF, Chen YC, Su CY. Treatment of vitreous floaters with neo-dymium YAG laser. Br J Ophthalmol 1993; 77: $485-488$.

46 Aron-Rosa D, Greenspan DA. Neodymium: YAG laser vitreolysis. Int Ophthalmol Clin 1985; 25: 125-134.

47 Fankhauser F, Kwasniewski SF, van der Zypen E. Vitreolysis with the Q-switched laser. Arch Ophthalmol 1985; 103: 1166-1171.

48 Puliafito KA, Wasson PJ, Steinert RF. Neodymium-YAG laser surgery on experimental vitreous membrane. Arch Ophthalmol 1984; 102: 843-847.

49 Jampol LM, Goldberg MF, Jednock N. Retinal damage from a Q-switched YAG laser. Am J Ophthalmol 1983; 96: 326-329.

50 Jagger JD, Hamilton AM, Polkinghorne P. Q-switched neodymium YAG laser vitreolysis in the therapy of posterior segment disease. Graefes Arch Clin Exp Ophthalmol 1990; 228: 222-225.

51 Little HL, Jack RL. Q switched neodymium: YAG laser surgery of the vitreous. Graefes Arch Clin Exp Ophthalmol 1986; 224: 240-246.

52 Cowan LA, Khine KT, Chopra V, Fazio DT, Francis BA. Refractory open angle glaucoma after Nd:YAG laser lysis of vitreous floaters. Am J Ophthalmol 2015; 159: 138-143. 